\title{
Megaeventos Esportivos
}

Otavio Tavares*

\begin{abstract}
Resumo: Em face da realização da Copa do Mundo de futebol da FIFA em 2014 e dos Jogos Olímpicos em 2016 no Brasil, 'megaevento' e 'legados' tornaram-se termos bastante presentes em nosso cotidiano, gerando um número crescente de debates e investigações. Neste texto, a partir da noção de que estes termos não estão ainda adequadamente compreendidos, reviso a definição sobre 'megaevento' e as conclusões até agora existentes sobre seus legados presentes na literatura. Isto permite apontar alguns elementos e questões para debates e intervenções cientificamente mais sólidos.
\end{abstract}

Palavras-chave: Megaeventos. Legados. Copa do mundo. Jogos olímpicos

\section{INTRODUÇÃo}

A proximidade da organização no Brasil da Copa do Mundo de futebol da FIFA em 2014 e dos Jogos Olímpicos em 2016 trouxe para nosso cotidiano um termo antes pouco conhecido e utilizado: 'megaevento'. Quase todos os dias nos deparamos com este termo nos veículos de comunicação, nos discursos dos políticos, dos administradores e dos empresários, mas também do homem comum. Podemos dizer que, com um misto de admiração, traduzida nos discursos triunfalistas a respeito da organização da Copa do Mundo e, especialmente, dos Jogos Olímpicos como 'prova' do caráter de potência emergente do Brasil, e espanto, corporificado nas críticas

"Programa de Pós-Graduação em Educação Física da Universidade Federal do Espírito Santo (UFES). Vitória, ES, Brasil. E-mail: tavaresotavio@yahoo.com.br 
ao volume de recursos públicos investido nestes eventos, nas suspeitas sobre sua gestão, na preocupação com as instalações específicas e a infra-estrutura necessária, entre outras questões, o país se viu e se vê na condição e na responsabilidade de sediar os dois maiores eventos esportivos mundiais no curto intervalo de dois anos. Mas não só eles. Os Jogos Pan-Americanos realizados em 2007 e os Jogos Mundiais Militares, realizados em 2011, ambos na cidade do Rio de Janeiro, assim como a Copa das Confederações de futebol da FIFA e os Jogos Mundiais dos Trabalhadores a serem realizados em 2013, se alinham aos outros eventos ensejando, inclusive, curiosas denominações para o período de realização deste conjunto de competições. "Tsunami esportivo" (BRASIL..., 2009, p. 1) e "Cometa do Desporto" (SILVA, 2011, p. S1), são algumas das metáforas que tentam traduzir em palavras o impacto esperado de tão extenso conjunto de grandes competições esportivas em um espaço de tempo relativamente curto ${ }^{1}$.

Assim, não é coincidência que, gradativamente, uma parte do mundo acadêmico nacional comece também a dedicar seu tempo e seus recursos em esforços de análise, compreensão, crítica e perspectivação dos chamados megaeventos esportivos. Tomando os Jogos Olímpicos e a Copa do Mundo de futebol como as referências privilegiadas do que é um megaevento esportivo e considerando apenas a análise destes eventos a partir de tal perspectiva, ela ganha em volume de produção e amplitude de abordagem nos últimos 5 anos especialmente, embora iniciativas pioneiras, em livros, de caráter mais global, mas que não tratam destas competições como megaeventos propriamente ditos, sejam conhecidas (NETTO, 193?; DaCOSTA, 1969; DaMATTA et al., 1982; TAVARES; DaCOSTA, 1998). Comparando com o que acontece no plano internacional, o fenômeno não é muito diferente. Segundo Horne e Manzenreiter (2006), embora sejam registrados

\footnotetext{
'Não deixa de ser curioso pensar que as analogias empregadas implicam em conotações bastante distintas e, provavelmente, diferentes daquelas que conscientemente seus criadores desejavam empregar. Afinal, um tsunami (uma onda gigante) causa impacto pelo potencial destrutivo e mortal, enquanto um cometa, embora belo e inspirador, raríssimas vezes causa efeitos concretos sobre a vida na Terra.
} 
trabalhos anteriores, a discussão sistemática de competições esportivas como megaeventos torna-se significativa apenas a partir do ano 2000. Contudo, o número de pesquisas é bastante mais elevado.

Uma pesquisa em cinco dos principais periódicos científicos nacionais da área da Educação Física (Pensar a Prática, Revista Brasileira de Ciências do Esporte, Revista da Educação Física/UEM, Revista Movimento e Motriz) tendo como referência de busca o termo "megaevento" teve como resultado a indicação de apenas 3 artigos (ALMEIDA; MARCHI JUNIOR, 2010, LIMA; MARTINS; CAPRARO, 2009, SILVA; LOPES; NETTO, 2010)². É importante assumir o caráter arbitrário do recorte da revisão de literatura. Como sabemos, os Jogos Olímpicos e as Copas do Mundo de futebol, como fatos sociais totais, geram como conseqüência a possibilidade de uma pluralidade de abordagens bastante mais ampla. Com efeito, quando utilizamos na busca os termos "jogos olímpicos", "olimpíadas" e "copa do mundo" obtivemos um total de 143 títulos ${ }^{3}$. A esta busca deve ser somada a edição $n^{\circ}$. 32/33 da revista Motrivivência (2009), inteiramente dedicada prospecção e especulação dos impactos dos megaeventos no Brasil e que nessa edição teve artigos relacionados a urbanismo, mídia, políticas públicas, economia, sociabilidades, imagem e identidade nacional, educação física escolar e educação olímpica.

A produção em livros revela-se também bastante limitada. Descontadas as publicações pioneiras anteriormente mencionadas, conta-se até aqui, salvo engano, com apenas duas publicações relacionadas ao tema. A primeira é "Megaeventos Esportivos, Legado e Responsabilidade Social". Esta obra, que é produto do II Seminário de Estudos Olímpicos, realizado em 2007 na Universidade de São Paulo sob coordenação da Profa. Kátia Rúbio, reuniu 19 autores

\footnotetext{
${ }^{2} \mathrm{O}$ sítio da revista Motriz indica ainda três edições de suplementos que são na verdade anais do Congresso Internacional de Educação Física e Motricidade Humana.

${ }^{3}$ Segundo nossa análise, um número bem menor de artigos $(n=11)$ pode ser considerado como apresentando abordagens que contribuem para a compreensão destes eventos e suas conseqüências e legados a partir de sua condição 'mega', entretanto, tais artigos não serão considerados em função dos limites deste texto.
} 
nacionais e um do exterior, apresentando múltiplas dimensões dos megaeventos e seus legados a partir da experiência dos Jogos PanAmericanos do Rio de Janeiro em 2007.

A segunda publicação é o livro "Legados de Megaeventos Esportivos", cuja pretensão declarada é "levantar o estado da arte dos conhecimentos produzidos sobre megaeventos e legados no exterior e no Brasil" (DaCOSTA; MIRAGAYA, 2008, p. 39) assumindo o foco no legado como corolário do evento. Uma vez que existe convergência sobre o elevado número de trabalhos no exterior sobre o tema (HORNE; MANZENREITER, 2006, PREUSS, 2007), o atingimento deste objetivo parece ser válido apenas para o Brasil. Vale destacar que a obra tem um caráter singular por reunir 75 autores do mundo acadêmico e do poder público federal, estes últimos geralmente resistentes à crítica e ao contraponto que caracterizam a atividade intelectual. A montagem desta articulação foi baseada no contato de autores nacionais e estrangeiros que pudessem discutir conceitos e experiências segundo padrões científicos e gestores públicos com envolvimento prático, conhecimento tácito e orientação política durante o Seminário 'Gestão de Legados de Megaeventos Esportivos' realizado em maio de 2008, na cidade do Rio de Janeiro, com suporte do Ministério do Esporte, Conselho Federal de Educação Física, Serviço Social do Comércio / RJ, Serviço Social da Indústria e Universidade Gama Filho.

Assim, apesar do número aparentemente crescente de pesquisadores dedicados a temática, as revisões da produção do conhecimento ora existentes indicam que "o foco quer em megaeventos ou legados tem sido limitado" (DaCOSTA; MIRAGAYA, 2008, p. 38) o que, em parte, pode estar relacionado à distância concreta entre o fenômeno dos megaeventos e o cotidiano dos esporte e da Educação Física no país até bem pouco tempo. De qualquer modo, apesar de registrarmos candidaturas olímpicas mais consistentes desde a segunda metade dos anos 1990, "a produção [sobre megaeventos] ainda é restrita, com esforços pontuais para o 
desenvolvimento dessa área de investigação inspirados pela realização do Rio 2007" (ALMEIDA; MEZZADRI; MARCHI JUNIOR, 2009, p. 182) $)^{4}$.

A realização da Copa do Mundo de futebol da FIFA em 2014 e dos Jogos Olímpicos no Rio de Janeiro em 2016, lastreadas no apoio convicto dos governos (SILVA, 2008; FILGUEIRAS, 2008), da indústria da comunicação de um modo geral (GURGEL, 2009; TAVARES, 2009) e dos dirigentes esportivos podem obscurecer as evidências da literatura que indicam a superestimação dos impactos positivos e a subestimação dos impactos negativos (HORNE; MANZENREITER, 2006; NEW ZEALAND TOURISM RESEARCH INSTITUTE, 2007; SOUZA; MARCHI JUNIOR, 2009), as lacunas identificadas na produção do conhecimento devem ser atacadas pela ampliação e a qualificação da produção do conhecimento sobre megaeventos esportivos no país, seja para refinar o potencial crítico da reflexão intelectual, seja para potencializar a contribuição acadêmica para gestão dos megaventos em suas diversas dimensões.

O presente artigo se serve de revisões da produção academica nacional e internacional para problematizar o tema 'megaeventos', na tradição dos 'temas polêmicos' deste periódico. Sem a pretensão e a condição de ser exaustivo nesta empreitada, pretendo que esta contribuição apresente mais questões do que respostas, potencializando assim a continuidade do debate e da crítica.

\section{0 que faz um megaevento 'Mega'?}

O emprego generalizado de um termo ou expressão pode significar uma compreensão igualmente generalizada do que ele quer dizer? No senso comum, o termo 'megaevento', tem sido genericamente empregado como um sinônimo de grandes competições esportivas, daí porque frequentemente ele aparece adjetivado como

${ }^{4} \mathrm{Na}$ realização deste texto, não foram considerados congressos e seminários cuja temática tenha sido a dos megaeventos, embora se reconheça a realização de alguns recentemente. 
"esportivo". Uma abordagem dedutiva a partir do que tem sido publicado na mídia em geral indica que têm sido chamados de megaeventos esportivos competições internacionais que reúnem um número de atletas que atinge a casa dos milhares em um espaço de tempo de um mês, no máximo, com potencial de impacto em diferentes setores da sociedade e que possui significativa carga simbólica.

A revisão empreendida para este texto indica, entretanto, uma ausência quase absoluta de conceituação do termo "megaevento" na produção nacional. Não é de fato surpreendente que textos não acadêmicos façam uso do termo sem evidenciar maiores necessidades de definição e esclarecimento sobre o que é um megaevento, mas é digno de nota que uma grande parte dos textos acadêmicos sobre megaeventos publicados em nosso país também não o faça. Podemos supor que o foco na questão dos legados tenha contribuído para que os autores deixassem esta questão de lado, ou que, tal como a mídia, partem do princípio de que haveria um entendimento tácito compartilhado que dispensa definições mais rigorosas ${ }^{5}$. Mas, como veremos, os esforços de conceituação indicam que o entendimento do que é um megavento não é tão evidente assim.

Para DaCosta; Miragaya (2008, p. 36) um megaevento pode ser definido pelo número de participantes ou pelo 'processo', o que para eles significa: "curta duração, porém de preparação longa e por vezes intermitente, sempre operando em escala de milhões de participantes". Isto permite que estes autores, tendo como referência as competições esportivas, classifiquem como megaeventos os Jogos Latino-Americanos do Rio de Janeiro em 1922, os Jogos os Jogos Mundiais Universitários em Porto Alegre e os Jogos Pan-Americanos de São Paulo, ambos em 19636 , as campanhas do Esporte Para Todos nos anos 1970, o carnaval brasileiro, as corridas de Fórmula 1, o Dia do Desafio e os Jogos do Serviço Social da Indústria (SESI).

\footnotetext{
${ }^{5}$ As exceções notadas foram os textos de Almeida; Mezzadri; Marchi Junior (2009), DaCosta (2002) e DaCosta; Miragaya (2008).

${ }^{6}$ Uma análise destas competições como megaeventos pode ser encontrada em Mazo (2007; 2008)
} 
Segundo Roche (apud HORNE; MANZENREITER, 2006, p. 2) "megaeventos são melhor compreendidos como eventos culturais (inclusive comerciais e esportivos) de larga escala, os quais têm um caráter dramático, apelo popular de massa e significado internacional". Os megaeventos podem ser considerados marcos da modernidade com longa tradição de integrar interesses industriais e corporativos com aqueles de governos em relação ao desenvolvimento urbano e imagem nacional (SCHIMMEL, 2006).

Em síntese, megaeventos apresentam

grandiosidade em termos de público, mercado alvo, nível de envolvimento financeiro do setor público, efeitos políticos, extensão de cobertura televisiva, construção de instalações e impacto sobre o sistema econômico e social da sociedade anfitriã (HALL, 2006, p. 59)

A partir desta definição, podemos aceitar a idéia de megaevento não-esportivo, daí porque a necessidade de adjetivação. Hall (2006) afirma que, historicamente falando, Feiras e Exposições internacionais são, junto com os Jogos Olímpicos, os modelos fundamentais do que devemos entender como megaeventos ${ }^{7}$.

Todavia, a revisão de literatura feita por Horne; Manzenreiter (2006) indica que no plano internacional, há convergência sobre três grandes razões para a expansão e o crescimento dos Jogos Olímpicos e da Copa do Mundo de futebol como megaeventos prototípicos enquanto que as exposições e feiras internacionais deslocam-se para uma posição menos proeminente. Em primeiro lugar, o avanço das tecnologias de comunicação tornou possível o surgimento do fenômeno da audiência em escala planetária ampliando as possibilidades de impacto e exploração dos eventos esportivos além de quaisquer outros. Em segundo lugar, a transmissão internacional

\footnotetext{
${ }^{7}$ Como sabemos a segunda e a terceira edições dos Jogos Olímpicos da era moderna (1900 e 1904) ocorreram em meio a Feiras Internacionais, como parte delas. No Brasil, a 'Exposição Internacional do Centenário da Independência' de 1922 teve, entre seus eventos, a realização dos Jogos Latino-Americanos no Rio de Janeiro, um torneio internacional de futebol e Jogos Militares (NETO-WACKER; WACKER, 2010). Este evento reuniu 1200 atletas de 6 países diferentes, tendo tido um público estimado de 162 mil espectadores (TORRES, 2006).
} 
destes eventos estimulou a construção de uma articulação entre direitos exclusivos de transmissão, direitos de patrocínio e possibilidades amplas de 'merchandizing' estabelecendo uma espécie de aliança entre COI e FIFA, o setor de comunicação e diferentes setores do mundo dos negócios na exploração das possibilidades negociais da vasta audiência global que a Copa do Mundo e os Jogos Olímpicos oferecem. Em terceiro lugar, os megaeventos esportivos passaram a serem vistos como oportunidades de promoção para cidades e países em termos de legados econômicos, urbanísticos, sociais, culturais, ambientais e esportivos, entre outros, o que explica o envolvimento de governos nas candidaturas e organização de megaeventos esportivos. Este conjunto de fatos faz com que a Copa do Mundo de Futebol e os Jogos Olímpicos engendrem inversões financeiras, interesses públicos e privados, impactos sociais e audiência global não alcançáveis por nenhum outro evento conhecido.

Neste contexto, revisores da produção do conhecimento como Almeida; Mezzadri; Marchi Junior (2009, p. 181) sugerem que os megaeventos se constituem em "campo fértil de investigação de relações sociais complexas e paradoxais da sociedade moderna". Considerando esta complexidade na dimensão específica dos megaeventos esportivos Horne; Manzenreiter (2006, p. 1-2) afirmam que,

just as modern competitive sport and large-scale sport events were developed in line with the logic of capitalist modernity, sports mega-events and global sport culture are central to late modern capitalist societies. As media events, the Summer Olympic Games and the FIFA association football World Cup provide cultural resources for reflecting upon identity and enacting agency. More generally they provide resources for the construction of 'a meaningful social life in relation to a changing societal environment that has the potential to destabilize and threaten these things' (Roche, 2000: 225). Sports 'mega-events' are important elements in the orientation of nations to international or global society. As Munoz suggests [...], mega-events, such as the Olympic Games, have also had an important

Movimento, Porto Alegre, v. 17, n. 03, p. 11-35, jul/set de 2011. 
role in the transformation of the modern urban environment, as a conveyor of architectural design traditions. Hence sport, here in its mega-event form, comes to be an increasingly central, rather than peripheral, element of urban modernity.

\section{LEGADOS DE MEGAEVENTOS?}

Não parece ser possível falar de megaeventos sem considerar, debater e avaliar seus legados. Em face dos altos custos diretos e indiretos para sua realização e do potencial de impacto, qualquer que seja ele, de um megaevento na região onde ele é realizado, a idéia de legado, ou seja, dos benefícios gerados em contraposição aos custos necessários, ocupa lugar central nesta discussão. Segundo Holger Preuss (apud POYNTER, 2006), foi apenas a partir da preocupação do Comitê Olímpico Internacional em contrabalançar a dimensão comercial dos Jogos Olímpicos com uma noção de valores e responsabilidade que a questão do 'legado' tornou-se central no ambiente olímpico. Comparativamente, a questão do legado possui bem menos importância no âmbito da FIFA. Esta relativa despreocupação da entidade dirigente do futebol mundial com um discurso de responsabilidade social de seu megavento está provavelmente relacionado ao fato de que, ao contrário do Comitê Olímpico Internacional, a FIFA desenvolveu muito pouco um discurso a respeito de valores do esporte como uma missão a promover por meio do futebol. Nos parece que, para ela, a Copa do Mundo é apenas esporte competitivo e negócio.

Apesar da promoção do esporte como ferramenta para o desenvolvimento humano estar inscrita como um dos princípios fundamentais do movimento olímpico ${ }^{8}$, a conclusão de Malfas et al. (apud HORNER; MANZENREITER, 2006, p. 9) após rever "a enorme quantidade de literatura sobre os impactos sócio-culturais,

\footnotetext{
${ }^{8}$ Os assim chamados princípios fundamentais do olimpismo e do movimento olímpico estão definidos na Carta Olímpica, a constituição do Comitê Olímpico Internacional. A Carta Olímpica está disponível em <http://www.olympics.org>
} 
sócio-econômicos, físicos e políticos dos Jogos Olímpicos é que os benefícios econômicos são o principal motivo em recebe-los".

De fato, não parece ser difícil encontrar nos discursos de autoridades governamentais em favor da Copa de 2014 e dos Jogos de 2016, argumentos e previsões sobre a geração de empregos e renda, o aumento da indústria do turismo, a projeção internacional do país e da cidade e a melhoria da qualidade de vida da população.

A realização com êxito dos Jogos Pan-Americanos e Parapan-Americanos 2007 torna inequívocos os diversos benefícios que podem ser alcançados e que devem ser revertidos para toda a sociedade na cidade sede, no Estado e no País. A infra-estrutura, o conhecimento, a tecnologia, entre outras áreas mobilizadas para a realização de um grande evento poderão potencialmente viabilizar o acesso de camadas significativas da população às políticas públicas em diversas áreas (FILGUEIRAS, 2008, p. 67).

Contudo, existem indicadores para pensarmos numa tendência a superestimação dos benefícios economicos e sociais assim como das rendas geradas e a subestimação dos custos e dos impactos (GRATTON; SHIBLI; COLEMAN, 2006). Uma primeira dificuldade para o desenvolvimento desta discussão é que o legado é multidisciplinar e dinâmico sendo afetado por uma variedade de fatores locais e globais (MORAGAS; KENNET; PUIG, 2003, PREUSS, 2007, PRONI, 2009). A avaliação dos impactos de megaeventos são "cheios de incertezas, multiplas variáveis e medidas subjetivas" (ROSE apud PREUSS, 2007, p. 14), assim, segundo Preuss (2007), a realização de previsões de legados a partir de casos anteriores são problemáticas mesmo quando realizados no mesmo país. De todo modo, como só é possível avaliar alguma coisa quando se define exatamente o que será avaliado, uma delimitação do que podem ser os legados de megaeventos torna-se fundamental.

Poynter (2006) apresenta uma proposta de definição de legados em duas grandes categorias iniciais: os legados tangíveis e os legados e intangíveis. Para este autor, pode ser considerado como legado 
tangível toda a infra-estrutura construida por causa do megaevento e não apenas aquela diretamente relacionada à sua realização, pois ela é suscetível a análise econômica de custo-benefício. Já o impacto cultural do megaevento pode ser considerado como um legado intangível, pois seus efeitos repercutem sobre a autoimagem do lugar e seus habitantes, as atitudes, a identidade projetada e outros aspectos sócio-culturais cuja mensuração exata, para Poynter, é mais duvidosa.

Nossa experiência pessoal indica que a categorização binária de Poynter, em função de sua facilidade de manipulação, tem tido boa aceitação no Brasil, tornando-se referência inicial em grande número de trabalhos já publicados (p. ex.: TAVARES, 2007; MAZO, 2008) e em produção ${ }^{9}$. Entretanto, ela parece ser claramente insuficiente em face da complexidade anteriormente mencionada.

Uma das listagens mais compreensivas de "possíveis legados" é aquela apresentada por Villano et al. (2008, p. 48-50) a partir do que estes autores definiram como "pontos de convergência destes debates em termos de incidência de abordagem pelos participantes e relevância identificada durante as apresentações e intervenções do seminário 'Gestão de Legados de Megaeventos Esportivos'" anteriormente aludido neste texto ${ }^{10}$. Como está claro pelo próprio adjetivo, os consensos abaixo listados indicam possibilidades ou oportunidades e não consequências necessárias da realização de grandes eventos.

a) Legados do evento em si

- construções esportivas: estádios, arenas e outros equipamentos;

- construções de infra-estrutura da cidade, como obras de transporte (metrô e etc.), alojamento de atletas;

- compras de equipamentos esportivos, de segurança, telecomunicações, informática, etc.;

${ }^{9}$ Refiro-me aos trabalhos apresentados em congressos e seminários recentes, mas ainda não publicados em periódicos científicos.

${ }^{10}$ Considero que, para os limites deste texto, o texto de Villano et al. serve como revisão dos textos sobre legados apresentados no livro "Legados de Megaeventos Esportivos" (2008)

Movimento, Porto Alegre, v. 17, n. 03, p. 11-35, jul/set de 2011. 
- ocupações de empregos temporários e/ou permanentes;

- abertura de novas possibilidades e oportunidades de trabalho especializado;

- promoção e realização de outros eventos;

- aumento da procura de práticas de atividades físicas por parte de população.

b) Legados da candidatura do evento

- aprendizado do processo de candidatura como, projetos, o processo em si e a organização prévia do evento;

- planejamento urbanístico da cidade-candidata que poderá ser utilizado pelo Poder Público, independente da realização do evento.

c) Legados da Imagem do Brasil

- projeção da imagem do país;

- projeção da imagem da cidade-sede dentro e fora do país, considerada como cultura urbana;

- projeção de oportunidades econômicas e de serviços que o país poderá oferecer;

- nacionalismo e confiança cívica, bem como o orgulho regional e nacional.

d) Legados de governança

- planejamento participativo;

- cooperação de diferentes órgãos administrativos;

- parceria público- privada;

- liderança do poder público local.

d) Legados de conhecimento

- treinamento e capacitação do pessoal envolvido na gestão do megaevento, desde gerente até voluntários (Know-how);

- ecos do voluntário que sugere a transmissão dos conhecimentos 
adquiridos por eles para sua comunidade, podendo se estender até na família e comunidade;

- transferência de conhecimento adquirido na gestão do evento (antes, durante e após) para futuros eventos similares;

- geração de informações e conhecimentos das instituições organizadoras do evento como, banco de dados, relatórios e outros, que poderão dar origem à produção de pesquisas científicas tanto nas universidades como em outros órgãos públicos e privados de fomento à pesquisa, inclusive, para possíveis publicações;

- desenvolvimento de estratégias para a contextualização do megaevento;

- referencial longitudinal para planejamento, execução e avaliação de intervenções, visando o desenvolvimento de legados e o estabelecimento de suas diretrizes;

- construção de estruturas adequadas, visando o aproveitamento futuro pela população

Uma limitação das contribuições de Poynter (2006) e Villano et al. (2008) reside no fato de não desenvolverem concretamente a possibilidade de efeitos negativos na realização de megaeventos embora os considerem teoricamente. Todavia, não parece razoável desconsiderar que, seja por eventos e efeitos não previstos nos projetos, seja porque a realização de "jogos de poder ao invés do compromisso com ideais deliberativos é o que frequentente caracteriza o desenvolvimento de megaprojetos" (FLYVBJERG et al. apud HORNE; MANZENREITER, 2006, p. 10) ou pela consecução de interesses privados tomados como interesses públicos (GRUNEAU apud HORNE; MANZENREITER, 2006, p. 8) muita coisa pode dar errado. Uma vez que revisões internacionais da literatura tem indicado a efetiva ocorrência desta possibilidade, Preuss (2007) estabelece uma distinção entre 'legados' e 'impactos' de megaeventos de modo a acomodar a previsão de possíveis efeitos negativos da realização do megaevento. O quadro abaixo, reproduzido de Preuss (2007, p. 23) sumariza 36 impactos em potencial segundo 4 categorias que podem apresentar tanto aspectos positivos quanto 
seu reverso segundo uma revisão de literatura feita pelo próprio autor.

Quadro 1 - Impactos

\begin{tabular}{|c|c|c|}
\hline Tipo de impacto & Positivo & Negativo \\
\hline Físico / ambiental & $\begin{array}{ll}\text { - } & \text { Construção de novas estruturas } \\
\text { - } & \text { Preservação do patrimônio } \\
\text { - } & \text { Promoção ambiental } \\
\text { - } & \text { Impactos esportivos }\end{array}$ & $\begin{array}{ll} & \text { Prejuízos ecológicos } \\
\text { - } & \text { Mudanças em processos } \\
\text { - } & \text { naturais } \\
\text { - } & \text { Deluição arquit etônica } \\
\text { - } & \text { Superlotaçãa do patrimônio } \\
\text { - } & \text { Estruturas não utiliza das } \\
& \text { (elefantes brancos) }\end{array}$ \\
\hline Social / cultural & 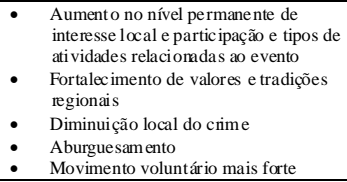 & $\begin{array}{l}\text { - } \quad \text { Comercialização de atividades } \\
\text { - } \quad \text { Pue eram li vres } \\
\text { - } \quad \text { Mudanças na estrutura da } \\
\text { comunid ade } \\
\text { - } \quad \text { aburguesamento } \\
\text { Deslocamento social }\end{array}$ \\
\hline 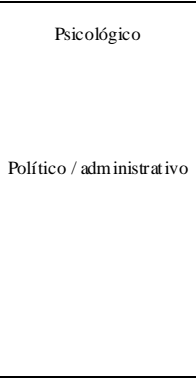 & 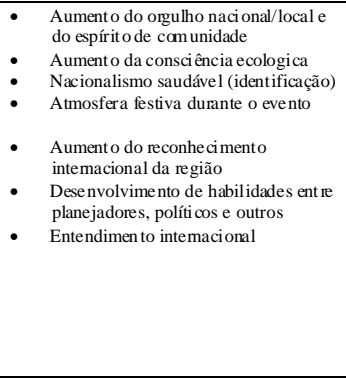 & $\begin{array}{ll}\text { - } & \begin{array}{l}\text { Tendência a atitudes } \\
\text { defensi vas tratando da região } \\
\text { sede }\end{array} \\
\text { - } & \text { Choque cul tural } \\
\text { - Manipulação comercial } \\
\text { - } \quad \begin{array}{l}\text { Exploração economica da } \\
\text { população local / le gitimar } \\
\text { decisões impopulares }\end{array} \\
\text { - } \quad \begin{array}{l}\text { Distorção da real natureza do } \\
\text { evento para refletir valores } \\
\text { das elites }\end{array} \\
\text { - Inabilidade em ati ngir os } \\
\text { objet ivos } \\
\text { - Aumento nos cust os } \\
\text { admi nistrativos } \\
\text { Corrupção }\end{array}$ \\
\hline
\end{tabular}

Fonte: PREUSS, 2007, p. 23

Outra revisão de literatura, provavelmente a mais ampla, sobre os efeitos do megaeventos foi produzida pelo New Zealand Tourism Research Institute (2007) ${ }^{11}$. Definida como uma bibliografia anotada, ela sumariza as conclusões de 111 estudos publicados em língua inglesa sobre os prováveis impactos e benefícios econômicos, sócioculturais, ambientais e de saúde de eventos esportivos, assim apresentados.

a) Impactos econômicos:

- Eventos são uma ferramenta privilegiada por um número cada vez maior de cidades e regiões em busca de desenvolvimento do turismo;

${ }^{11}$ Segundo os autores, foram consultados 8 bases de dados e 23 periódicos com a utilização de 20 termos de busca. Todos os artigos considerados foram publicados entre 1997 e 2007, tiveram revisão pelos pares e apresentavam metodologia de pesquisa definida e compatível (PREUSS, 2007, p. 67). 
- A maior parte das evidências que afirmam que os eventos têm um impacto significativo sobre a economia provavelmente são baseados em estudos metodologicamente deficientes, assim como não existe consenso sobre o melhor método para medir os impactos e benefícios dos eventos.

- Mensurações ex post são melhores do que medidas ex ante para avaliar impactos / benefícios econômicos. Existem dificuldades em transferir os resultados da avaliação de impactos / benefícios de um evento para outro;

- Existe um ceticismo crescente na mídia e nos circulos acadêmicos na capacidade de um megaevento gerar impactos/ benefícios. Nem todos os envolvidos (stakeholders) compartilham igualmente os custos e benefícios do evento. Por outro lado, os impactos são maximizados quando governo, organizadores e setor privado interagem efetivamente;

- Renovação urbana e desenvolvimento de infraestrutura são estímulos-chave para cidades que desejam receber megaeventos. Contudo, apesar da retórica sobre a criação de legados, foram encontrada deficiências nas fases iniciais de desenvolvimento do evento de planejamento de longo prazo sobre o pós-evento;

- Eventos esportivos têm potencial para construir a marca de uma cidade ou região, porém eles devem estar estrategicamente incorporados a um plano geral de marketing turístico.

b) impactos sócio-culturais

- Existe a necessidade de mais pesquisas sobre o valor social de um megaevento e como as comunidades o avaliam;

- O apoio da comunidade é essencial para o sucesso de um megaevento;

- A maioria dos residentes provavelmente apoia a realização do evento. $\mathrm{O}$ apoio será maior a medida em que perceberem que irão ter algum benefício do evento. Melhora do orgulho da 
comunidade, trocas culturais, elevação do perfil da cidade, da autoestima e do senso de comunidade são os resultados sociais positivos mais citados;

- Estudos longitudinais mostram que as pessoas tendem a esperar um nível maior de impactos negativos do que realmente experimentam. Por outro lado, os moradores tendem a se entusiasmar mais com o evento do que imaginavam antes;

- A oposição é maior entre aqueles que vivem mais próximo do evento e entre aqueles que não tem interesse nele;

- As comunidades têm consciência crescente de estarem sendo usadas em prol de elites economicas e políticas que lucram as expensas da comunidade local;

- Há poucas evidências de que a criminalidade suba durante um megaevento;

- Há pouca probabilidade de que o voluntariado para o megaevento aumente o nível de voluntariado na comunidade de um modo geral.

c) Impactos ambientais

- Existe a necessidade de mais pesquisa sobre os impactos ambientais dos megaeventos;

- Gerenciamento de lixo, consumo de energia, transporte, reciclagem de materiais e impacto negativo no meio-ambiente estão entre as questões ambientais provavelmente mais associadas a realização de um megaevento;

- Não existe literatura que associe os megaventos a questão das mudanças climáticas;

- Atividades de lazer que os visitantes fazem além do evento podem trazer mais dano ambiental do que a participação no próprio evento;

- A adoção de 'políticas verdes' parece estar institucionalizada em megaeventos. A própria realização dos eventos é vista como 
uma oportunidade para desenvolver conscientização e tecnologia para a sustentabilidade;

- A cooperação entre os diferentes atores envolvidos no megavento pode garantir uma implementação mais tranquila de medidas ambientais. $\mathrm{O}$ envolvimento de organizações ambientalistas no planejamento pode diminuir as preocupações com o impacto ambiental. Por outro lado existe crescente ceticismo para com objetivos ecológicos muito publicizados.

d) Impactos na saúde [sic]

- Existem evidências de que os sistemas de monitoramento e controle da saúde pública são criados ou ampliados durante os megaeventos;

- Não existem evidências de que os eventos germ aumento no nível de atividade física ou na participação esportiva;

- Existem dificuldades de estabelecer ligação entre um megaevento e a participação esportiva de massa. Existe a necessidade de mais pesquisas nesta área;

- Atividade física e participação esportiva não são provavelmente afetados a menos que o megaevento seja envolvido em uma estratégia de desenvolvimento de longo prazo. As organizações esportivas estão sempre despreparadas para captalizar as oportunidades geradas pelo evento.

Em face das revisões aqui mencionadas, confirma-se o caráter ambivalente dos impactos da realização de megaeventos. Há em toda a literatura consultada o reconhecimento de que podem existir efeitos políticos, econômicos, sócio-culturais e ambientais positivos e negativos. Ou seja, existem 'vencedores' e 'perdedores' na realização dos Jogos Olímpicos e da Copa do Mundo (TAVARES, 2005; PREUSS, 2007).

De modo mais específico, notou-se, porém, a inexistência de menções relativas a impactos na educação de um modo geral e na Educação Física escolar particularmente. Isto sugere que muito pouca atenção na literatura internacional é dada aos impactos educacionais 
de megaeventos? Ou, este quadro é efeito dos recortes da revisão de literatura? Este é um dado que merece ser melhor investigado pois não há razões para duvidarmos das extensas possibilidades de relações que se podem fazer entre eventos esportivos e a educação (p. ex.: BETTI, 2009; BRACHT; ALMEIDA, 2003; HATZIDAKIS, 2008; RUBIO, 2009; TODT, 2008). A mesma ausência foi notada no que se refere aos legados do megaeventos esportivos para o desenvolvimento do sistema esportivo de alta competição. Enquanto são encontráveis estudos a respeito dos impactos dos megaeventos em relação a participação esportiva de massa, pouco se sabe a respeito dos efeitos da organização destas competições para o sistema esportivo local.

\section{Concluindo?}

Arealização da Copa do Mundo da FIFAe dos Jogos Olímpicos são fatos dados. Diante disto, não se trata mais de debater sobre a pertinência ou não de realiza-los. Cabe a comunidade acadêmica ocupar alguma de três posições legítimas. A de produtora de análises críticas destinadas a produzir compreensões a respeito das diferentes dimensões que um evento desta escala alcança, problematizando projetos e processos, identificando contradições, efeitos perversos, exclusões e etc. A de produtora de conhecimentos que auxiliem a gestão dos eventos, contribuindo no plano da intervenção e fornecendo dados e expertises para a solução de problemas, reduzindo gastos, aumentando a eficiência, prevenindo efeitos perversos, exclusões e etc. Ou, por fim, a de permanecer distante do assunto, se ocupando de tantas outras questões relevantes para a Educação Física e as Ciências do Esporte. As duas primeiras envolvem muitas questões e desafios.

Em face do que vimos anteriormente, apresento algumas afirmações que podem ser tomados como questões. Assim, podem estimular novos debates por outros autores nesta revista. As primeiras relacionadas a produção do conhecimento, as últimas voltadas para a realização dos próprios megaeventos. 
No que se refere a produção do conhecimento, é necessário desnaturalizar as noções de megaeventos e de legados por meio de sua problematização. A ausência de definições conceituais para ambos os termos é um fato que representa sério risco para o desenvolvimento de um debate acadêmico de qualidade. Neste contexto, parece ser produtivo um maior diálogo com a produção feita em outros países. Se a experiência de legados e impactos é pouco transferível, o referencial teórico e as experiências de pesquisa anteriormente realizadas podem perfeitamente servir de referência. É preciso também avançar do conhecimento tácito para o conhecimento empírico sobre megaeventos e seus legados. Uma boa parte da produção nacional até agora ${ }^{12}$ caracteriza-se por ensaios ou revisões de literatura, ainda que se reconheça algum avanço a partir da realização do Pan Americano de 2007. Em razão de seu caráter multifacetado, a investigação sobre megaeventos permite, se não exige, intersecções e superposições de saberes e interesses, o que indica a necessidade de complementaridade teórica e pluralidade metodológica. Neste aspecto, a tradição acadêmica de mediação da Educação Física / Ciências do Esporte parece lhes garantir uma experiência privilegiada. Por fim, sugere-se o desenvolvimento de pesquisas a respeito dos impactos e legados de megaeventos para a Educação Física escolar e para o sistema esportivo de alta competição. São dimensões bastante diferentes, quase opostas que, curiosamente, parecem estar unidas na pouca atenção dada a eles até agora.

No que se refere a realização dos próprios megaeventos, quero deixar claro que afirmar sua inevitabilidade não significa nenhum fatalismo ou a sugestão de abandono da questão em si. De fato, como a literatura sugere, muito do que se refere a realização de megaventos esportivos está relacionada a questões de cidadania, visão republicana e democracia, que são transversais a qualquer campo de saber determinado - embora sejam temas específicos da ciência política. Megaeventos são uma parte significativa da

\footnotetext{
${ }^{12}$ Inclusive a deste autor.
} 
experiência contemporânea, mas não podem ser vistos como uma panacéia para problemas econômicos e sociais. Eles requerem um tremendo investimento de recursos humanos, financeiros e físicos das sociedades que se dispõem a organiza-los que devem sempre estar sujetos ao debate e ao escrutínio públicos. Temos que reconhecer as demostrações públicas de preocupação por parte de membro da administração federal em realizar competições socialmente responsáveis.

[...] o maior legado dos megaeventos esportivos talvez não seja o espectadorismo dos jogos. Há outros benefícios que os megaeventos esportivos podem estender para toda população. Ampliar o olhar sobre essas possibilidades é uma das nossas tarefas enquanto representantes do Governo Federal, valorizando conhecimentos e tecnologias que possam qualificar ações políticas esportivas que atendam às necessidades e conquistem diferentes resultados positivos a curto, médio e longo prazos. Essa atitude, particularmente, é relevante para a avaliação das políticas que se voltam ao desenvolvimento do esporte desejado para o País como um todo. Mas, esse desenvolvimento, que pode ter diferentes efeitos e demandas requer, sobretudo, investimentos educativos, cujos ganhos são reconhecidamente certos, mas os efeitos não se fazem de imediato - de um dia para o outro (RODRIGUES; MAGALHÃES PINTO, 2008, p. 21).

Todavia, como fazer que esta preocupação não termine apenas em retórica? A articulação entre organizadores, patrocinadores e indústria da comunicação, somada ao desejo dos governos em fazer e somar pontos em sua agenda política pode tornar difícil o estabelecimento de qualquer medida que contrarie os interesses dos principais beneficiários da organização dos megaventos. Um sinal preocupante de que isto é mais do que uma possibilidade está no fato de que em função do 'momento especial' pelo qual o país vai 
passar podem-se, justificadamente, suspender desde o funcionamento de um aeroporto ${ }^{13}$ até as regras de licitações e licenciamento ambiental. Como sabemos, as regras especiais sãojustificadas pelos avanços prometidos como seu resultado. Assim, a mobilização para a realização dos grandes eventos pode estar criando "pontos cegos da idealização" (CONDE, 2011, p. 2), gerando, inclusive má vontade com aquilo que contradiz o discurso que parece ser da maioria. Como afirma Rolnik (2011, p. 6) "Esse eventos têm uma importância simbólica, têm um apelo nacionalista, mobilizam sentimentos que criam uma espécie de blindagem, como se para fazer isto acontecer valesse tudo". Neste contexto, como Flyvjberg (apud HORNE; MANZENREITER, 2006, p. 15) sugere "as armas chave contra uma cultura do embuste coberto envolvendo megaeventos são transparência, gestão responsável (accountability) e questionamento crítico de organizações e especialistas independentes". Este é um papel que, por certo, nos cabe à todos.

\footnotetext{
${ }^{13}$ Refiro-me a suspensão das operações do aeroporto Santos Dumont, no Rio de Janeiro, em 31 de julho de 2011, para o sorteio dos grupos das eliminatórias para a Copa do Mundo de 2014.
} 


Sport's Mega events
Abstract: Due to the hosting of FIFA's Football World
Cup in 2014 and the Olympic Games in 2016, 'mega
events' and 'legacies' became terms quite frequent in
our daily lives generating a growing number of
debates and investigations. In this text, from the notion
that these terms are not completely comprehended, I
review mega event's definitions and debates toward
their legacies presents on the literature. I could point
out some elements and questions to future debates
and investigations based on more sound theoretical
and methodological approach.
Keywords: Mega events. Legacies. World cup.
Olympic games

\section{Mega eventos deportivos}

Resumen: La realización del Mundial de Fútbol da FIFA en 2014 y de los Juegos Olímpicos en 2016 en Brasil han convertido 'megaeventos' y 'legados' en términos muy frecuentes en la vida cotidiana a la vez que generan un creciente número de debates e investigaciones. A partir de la noción de que estos términos no son entendidos de manera adecuada, reviso las definiciones de 'megaevento' y sus 'legados' presentes en la literatura. El reto es permitir el apunte de elementos y cuestiones que proporcionen debates e intervenciones científicamente más sólidas.

Palavras claves: megaeventos; legados; Mundial de Fútbol; Juegos Olímpicos

\section{REFERÊNCIAS}

ALMEIDA, B. S.; MARCHI JUNIOR, W. O financiamento dos programas federais de esporte e lazer no Brasil (2004 a 2008). Movimento, Porto Alegre, v. 16, n. 4, 2010.

ALMEIDA, B. S.; MEZZADRI, F. M.; MARCHI JUNIOR, W. Considerações Sociais e Simbólicas sobre Sedes de Megaeventos Esportivos. Motrivivência, Florianópolis, v. 21, n. 32-33, p. 178-192, jun./dez. 2009.

BETTI, M. Copa do Mundo e Jogos Olímpicos: inversionalidade e transversalidades na cultura esportiva e na Educação Física escolar. Motrivivência, Florianópolis, v. 21, n. 32-33, p. 16-27, jun./dez. 2009.

BRACHT, V.; ALMEIDA, F. Q. A política de esporte escolar no Brasil: a pseudovalorização da educação física. Revista Brasileira de Ciências do Esporte, São Paulo, v. 24, n. 3, p.87-101, 2003. 
BRASIL: Ponto de Encontro do Esporte Mundial. Revista de Educação Física, v. 8, n. 34, p. 1, dez. 2009.

CONDE, M. Os pontos cegos da idealização. O Globo, Rio de Janeiro, 6 ago. 2011. Caderno Prosa \& Verso, p. 2.

DaCOSTA, L. P. (Org.) XIX Olimpíada México 1968: aspectos técnicos evolutivos. Brasília: Divisão de Educação Física - MEC, 1969.

Olympic studies. Rio de Janeiro: Editora Gama Filho, 2002.

DaCOSTA, L. P.; MIRAGAYA, A. Estado da Arte do Conhecimento sobre Legados de Megaeventos Esportivos no Exterior e no Brasil. In: DaCOSTA, L. P. et al. (Ed.). Legados de megaeventos esportivos. Brasília: Ministério do Esporte, 2008. p. 33-45.

DaMATTA, R. et al. Universo do futebol São Paulo: Pinacotheke, 1982.

FILGUEIRAS, J. C. M. A Importância dos Legados de Megaeventos Esportivos para a Política Nacional de Esporte no Brasil: cidade, cidadania e direitos dos cidadãos. In: DaCOSTA, L. P. et al. (Ed.). Legados de Megaeventos Esportivos. Brasília: Ministério do Esporte, 2008. p. 65-74.

GRATTON, C.; SHIBLI, S.; COLEMAN, R. The economic impact of major sports events: a review of ten events in the UK. In: HORNE, J; MANZENREITER, W. (Ed.). Sports Mega-Events: social scientific analyses of a global phenomenon. (Special Issue: The Sociological Review Monograph Series) V. 54, Issue Suplement s2, December 2006. p. 41-58.

GURGEL, A. Desafios do jornalismo na era dos megaeventos esportivos. Motrivivência, Florianópolis, v. 21, n. 32-33, p. 193-210, jun./dez. 2009.

HALL, C. M. Urban entrepreneurship, corporate interests and sports mega-events: the thin policies of competitiveness within the hard outcomes of neoliberalism. In: HORNE, J; MANZENREITER, W. (Ed.). Sports Mega-Events: social scientific analyses of a global phenomenon. (Special Issue: The Sociological Review Monograph Series) V. 54, Issue Suplement s2, December 2006. p. 59-70.

HATZIDAKIS, G. S. Legado Educacional dos Jogos Pan Americanos e Parapan 2007: Instrumentalizando a escola. In: DaCOSTA, L. P. et al. (Ed.). Legados de Megaeventos Esportivos. Brasília: Ministério do Esporte, 2008. p. 395-402.

HORNE, J; MANZENREITER, W. An introduction to the sociology of sports megaevents. In: HORNE, J; MANZENREITER, W. (Ed.). Sports Mega-Events: Social Scientific Analyses of a Global Phenomenon. (Special Issue: The Sociological Review Monograph Series) V. 54, Issue Suplement s2, December 2006. p. 1-24.

LIMA, M. A. de; MARTINS, C. J.; CAPRARO, A. M. Olimpíadas Modernas: a história de uma tradição inventada. Pensar a Prática, Goiânia, v. 12, n. 1, 2009. 
KLEIN, M. A. O Brasil e seus desafios rumo a modernidade de seus eventos esportivos. In: RUBIO, K. (Org.). Megaeventos esportivos, legado e responsabilidade social. São Paulo: Casa do Psicólogo, 2008. p. 13-35.

MAZO, J. Z. Universíade de 63: qual o legado para a cidade de Porto Alegre? In: DaCOSTA, L. P. et al. (Ed.). Legados de Megaeventos Esportivos. Brasília: Ministério do Esporte, 2008. p. 429-430.

MORAGAS, M.; KENNET, C; PUIG, N. (Org.). The Legacy of the Olympic Games 1984-2000. Lausanne: IOC, 2003.

NETTO, A. R. Jogos Olímpicos de Hontem, de Hoje e de Amanhan. [s.l.]: SPES, 193?

NEW ZEALAND TOURISM RESEARCH INSTITUTE. The benefits of events: an annotated bibliography. [s.I.], 2007.

POYNTER, G. From Beijing to Bow Bells: Measuring the Olympic Effects (London East Research Institute. Working paper in Urban Studies). Londres: London East University, 2006.

PREUSS, H. Aspectos Sociais dos Megaeventos Esportivos. In: RUBIO, K. (Org.). Megaeventos esportivos, legado e responsabilidade social. São Paulo: Casa do Psicólogo, 2008. p. 13-35.

PRONI, M. W. Observações sobre os Impactos Econômicos Esperados dos Jogos Olímpicos de 2016. Motrivivência, Florianópolis, v. 21, n. 32-33, p. 49-70, jun./ dez. 2009.

RODRIGUES, R. P.; MAGALHÃES PINTO, L. M. S. de. Subsídios para pensar os Legados de megaeventos esportivos em seus tempos presente, passado e futuro. In: DaCOSTA, L. P. et al. (Ed.). Legados de Megaeventos Esportivos. Brasília: Ministério do Esporte, 2008. p. 21-25.

ROLNIK, R. As leis estão sendo desrespeitadas. O Globo, Rio de Janeiro, 6 ago. 2011. Caderno Prosa \& Verso, p. 6.

RUBIO, K. (Org.) Megaeventos esportivos, legado e responsabilidade social. São Paulo: Casa do Psicólogo, 2008.

O legado Educativo dos Megaeventos Esportivos. Motrivivência, Florianópolis, v. 21, n. 32-33, p. 71-88, jun./dez. 2009.

SCHIMMEL, K. S. Deep Play: sports mega-events and urban social conditions in the USA. In: HORNE, J; MANZENREITER, W. (Ed.) Sports Mega-Events: Social Scientific Analyses of a Global Phenomenon. (Special Issue: The Sociological Review Monograph Series) V. 54, Issue Suplement s2, December 2006. p. 160-174.

SILVA, C. A. F. da; LOPES, J. P. S. R.; NETTO, J. de A. Educação Física, desenvolvimento e inovação: o argumento da hélice tríplice. Motriz, Rio Claro, v. 16, n. 4, 2010. 
SILVA, F. A, e 5‥ Jogos mundiais militares. Motriz, Rio Claro, v. 17, n. 1 (Supl.1), p. S1-S523, jan./mar. 2011.

SILVA, O. A importância dos legados de megaeventos esportivos para a política nacional de esporte no Brasil. In: DaCOSTA, L. P. et al. (Ed.). Legados de Megaeventos Esportivos. Brasília: Ministério do Esporte, 2008. p. 19-20.

SOUZA, J. de; MARCHI JUNIOR, W. Os "Legados" dos Megaeventos Esportivos no Brasil: algumas notas e reflexões. Motrivivência, Florianópolis, v. 21, n. 32-33, p. 245-255, jun./dez. 2009.

TAVARES, E. A Copa e a Mídia: reflexões sobre a mais-valia ideológica, a soberania comunicacional e o jornalismo. Motrivivência, Florianópolis, v. 21, n. 32-33, p. 156-177, jun./dez. 2009.

TAVARES, O. Quem são os vencedores e os perdedores dos Jogos Olímpicos? Pensar a Prática, Goiânia, v. 8, n. 1, p. 69-84, 2005.

Instalações temporárias do Pan Rio 2007: possíveis legados. In: RUBIO, K.

(Org.). Megaeventos esportivos, legado e responsabilidade social. São Paulo: Casa do Psicólogo, 2008. p. 77-87.

TAVARES, O.; DaCOSTA, L. P. (Ed.). Estudos olímpicos. Rio de Janeiro: Editora Gama Filho, 1998.

TODT, N. S. Um País Olímpico sem Educação Olímpica? In: PREMIO BRASIL DE ESPORTE E LAZER DE INCLUSÃO SOCIAL. Coletânea dos Premiados de 2008. Brasília: Ministério do Esporte, 2009. p. 370-380.

TORRES, C. Jogos Olímpicos Latino-Americanos de 1922. In: DaCOSTA, L. P. (Org.). Atlas do Esporte no Brasil. Rio de Janeiro: Shape, 2006. p. 206-207.

VILLANO, B. et al. Seminário legados de Megaeventos esportivos: pontos de convergência. In: DaCOSTA, L. P. et al. (Ed.). Legados de Megaeventos Esportivos. Brasília: Ministério do Esporte, 2008. p. 47-50.

WACKER NETO, M. de F.; WACKER, C. Brazil Goes Olympic: Historical fragments from Brazil and the Olympic Movement until 1936. Kassel: Agon Sportverlag, 2010.

Endereço para Correspondência:

Otavio Tavares

UFES - CEFD / DG

Av. Fernando Ferrari, 514

29075-910 - Vitória, ES

Recebido em: 20-09-2011

Aprovado em: 19-10-2011

ovimento, Porto Alegre, v. 17, n. 03, p. 11-35, jul/set de 2011. 
